\title{
Air Contaminants in an Underwater Vehicle Cabin During Navigation
}

\author{
Jingjing FANG ${ }^{1}$, Kexian LI, Xinhong XU, Xiaomeng REN and Lu JIANG \\ Navy Medical Center, Second Military Medical University, Shanghai 200433, China
}

\begin{abstract}
The purpose of this study is to study the air contaminants in the cabins of underwater vehicle. The basic data help for the better research of the underwater vehicle cabin environment standard and the control strategy. Pretreatment and analysis method of volatile organic compounds was preconcentration combined with gas chromatography under the condition of liquid nitrogen and detected by chromatography-mass spectrometry. The pollution of particles, carbon monoxide and carbon dioxide during the underwater vehicle voyage were monitored by online monitoring instrument. Altogether 34 kinds of pollution components were detected, most of which were low in concentration. Some are low olfactory threshold or high toxic components, such as dimethyldisulfide, benzene, carbon disulfide, trichloromethane, and several reached to ppm level. The contamination of the particles was mainly fine particles and part cabins exceeded the national standard of indoor air quality. The highest concentration of carbon dioxide in accommodation space exceeded the permissible concentration of atmosphere composition aboard diesel underwater vehicle compartments. The increase submerged time made the environment in the cabins deteriorate. The concentration of trace contaminants may close to or beyond the relevant standards with the prolonged time. The volatile organic compounds, particles, carbon monoxide and carbon dioxide aggravated the air circumstance in the cabins. It should be determined the permissible concentration of air contaminants in underwater vehicle as soon as possible.
\end{abstract}

Keywords. Air contaminants, underwater vehicle, environment pollution

\section{Introduction}

When the underwater vehicle sails underwater, the crew lives in a specific environment, the space is small, the activity is limited, and the cabin lacks natural light and normal air circulation, plus swing, vibration, noise, high temperature, high humidity, biological rhythm, harmful Gas, nutrients, water supply and other factors will inevitably have a certain impact on human physiology and psychology. Conducting surveys on the navigation air quality data of such underwater vehicle can provide a scientific basis for strengthening medical support and formulating corresponding health standards in the future. There are many kinds of gas in the enclosed environment of the underwater vehicle cabin, which pollutes the air inside the boat and threatens the health of the crew. There are many sources of pollution in the boat, such as ammonia, formic acid, uric acid, aldehyde, methyl mercaptan, volatile amines and other harmful substances produced by human metabolites; cooking produces a large amount of acrolein, oxygenates and aerosols; non-metallic materials such as paints and plastics Rubber, fuel, lubricating oil,

${ }^{1}$ Corresponding Author, Jingjing FANG, Navy Medical Center, Second Military Medical University, Shanghai 200433, China; E-mail: 552417745@qq.com. 
and binders can produce a large number of harmful substances such as alkanes, olefins, halogenated hydrocarbons, aromatic hydrocarbons, oxygenates, sulfur compounds, aerosols, and the like. With the increasing number of non-metallic materials on the boat, these materials have become the main source of air pollutants in the cabin [1-4]. The harm of aerosol to human body is closely related to its particle size. Particles larger than $2.5 \mu \mathrm{m}$ are easily blocked by the respiratory tract, stimulating the local mucosa, causing allergic rhinitis, infecting the upper respiratory tract, and forming bronchial asthma, bronchitis, and allergic Pneumonia, and lead to respiratory dysfunction; and particles less than $2.5 \mu \mathrm{m}$ can directly enter the lungs, leading to lung sclerosis, and posing a great threat to the health of the crew [5].

The research on the atmospheric environment detection of underwater vehicle cabins has been valued by the navies of various countries. The US Navy ranks the importance of underwater vehicle air quality as the second only to defense preparations, which shows the importance attached to the quality of the atmospheric environment [6]. The Royal Navy also attaches great importance to the air detection technology of underwater vehicle cabins [7]. It has qualitatively analyzed 195 kinds of harmful gas components in the air of underwater vehicle cabins, and quantitatively analyzed 50 of them. Zhou Shengru used five kinds of adsorbents (Tenax, Porapak, Chromosob-103, GDX-101, and activated carbon) for concentration sampling, and 14 kinds of 266 organic substances were legally determined by color spectro scopy [8]. Xiao Cunjie divided the atmospheric components of the underwater vehicle into 12 categories, and concentrated and sampled the 12 substances using six adsorbents (Tenax, Porapak, Chromosob-103, GDX-101, activated carbon, and silica gel) [9]. Altogether 368 components were qualitatively detected, including 175 kinds of aliphatic hydrocarbons, 53 kinds of aromatic hydrocarbons, 28 kinds of naphthalenes and their homologues, 20 species of quinones and their homologues, 14 kinds of halogenated hydrocarbons, 2 kinds of nitrogen-containing compounds, 7 kinds of alcohols, 9 kinds of aldehydes, 16 kinds of ketones, 1 kinds of acid, 4 kinds of esters, 2 kinds of ethers and 37 others, by the method of Colorimetric mass spectrometry, verification tube, colorimeter and atomic absorption spectrometry, and 67 components were quantitatively detected. The Swedish Naval Institute of Defense, Lund University and other units studied the quality of the air during the dive of the Gotland-class AIP underwater vehicle, and jointly carried out a 16-day trial in which the snorkeling continued for 8 days [10]. In this experimental study, the monitor was carried out mainly including carbon dioxide $\left(\mathrm{CO}_{2}\right)$, oxygen $\left(\mathrm{O}_{2}\right)$, ozone $\left(\mathrm{O}_{3}\right)$, hydrogen $\left(\mathrm{H}_{2}\right)$, nitrogen dioxide $\left(\mathrm{NO}_{2}\right)$, volatile organic compounds (VOC), formaldehyde, suspended particulate matter (PM) and Microbial contaminants. Air temperature, total pressure and relative humidity were also monitored. Tests show that as long as the air renewal system works normally, except for carbon dioxide, all measured concentrations are much lower than the $8 \mathrm{~h}$ occupational exposure limit standard made by Swedish Environmental Protection Agency, and the monitored air pollutants do not accumulate. Researchers from the Australian Department of Defense's National Defense Science and Technology Organization have studied the particle properties and composition of diesel-electric underwater vehicle release, and the measurement of emissions from marine-derived diesel particulates is rare, although this form of transportation causes significant air pollution. However, unlike the terrestrial environment, the maritime environment is not disturbed by other sources of combustion. The average concentration of particulate matter in the diesel engine compartment is $1500 \mu \mathrm{g} / \mathrm{m}^{3}$, and the particle size distribution is in the range of $0.5-202 \mu \mathrm{m}$. The chemical forms of elemental carbon (EC), organic carbon (OC) and total carbon (TC) of the particulate matter are determined [11]. 
Researchers at the University of Antwerp in Belgium studied the contamination of particulate matter in diesel cabins, collected fine and coarse ions in the boat, and analyzed organic carbon, water-soluble organic carbon, main inorganic ion species and organic species, and estimated the concentration of sea salt particles, water soluble and water insoluble organic matter [12].

In order to study the composition and concentration of the main pollutants in the air of the Underwater Vehicle's cabin, airborne pollutants were detected and monitored for the underwater navigation test. The research on the quantitative analysis of air pollutants in such underwater vehicle s can provide a basis for future research on the standard limits of harmful gases for such underwater vehicle s and the design of marine air purification devices.

\section{Methods}

\subsection{Sampling Point Settings}

This type of underwater vehicle is equipped with an air renewal system for common air pollutants, a carbon dioxide elimination system using $\mathrm{LiOH}$ as an absorbent, and an activated carbon filter device for adsorbing volatile organic compounds and particulate matter. In this experimental study, volatile organic compounds (VOC), fine Particles $\left(\mathrm{PM}_{2.5}\right)$, inharable particulates $\left(\mathrm{PM}_{10}\right)$, and total suspended particulate matter (TSP) were monitored, and the temperature, humidity and pressure of air were recorded. The VOC collected a total of six representative points, accommodation space (AS), toilet (T), control room (CR), galley (G), energy source section (SS), machinery room (MR). The test was carried out tested in the later period of navigation, and the environmental equipment of each cabin of the navigation test worked well.

\subsection{Gas Analysis of VOC}

\subsubsection{Environmental Parameters}

Silicon-coated sampling tank (Entech USA) was used to enrich and measure the harmful gases in each cabin of the underwater vehicle. Before sampling, the sampling tank is cleaned and vacuumed with $\mathrm{N}_{2}$. The instantaneous sampling head is connected to the cleaned sampling tank by means of instantaneous sampling. After opening the valve, the air sample is automatically collected, and the $6 \mathrm{~L}$ sampling tank is collected in 5 minutes. The environmental conditions of each compartment at the time of sampling are shown in table 1. After the collection, the sampling valve is sealed and brought back to the laboratory for quantitative analysis after the end of the navigation.

Table 1. Environmental condition of sampling and monitoring.

\begin{tabular}{lllllll}
\hline Parameter & AS & T & CR & G & SS & MR \\
\hline Temperature $\left({ }^{\circ} \mathrm{C}\right)$ & $30.3-32.3$ & $29.6-32.8$ & $34.5-29.3$ & $38.3-42.3$ & 32.3 & 33.6 \\
Pressure $(\mathrm{KPa})$ & $100.9 \pm 0.4$ & $100.8 \pm 0.7$ & $100.5 \pm 0.9$ & $101.3 \pm 0.6$ & $101.4 \pm 0.4$ & $101.1 \pm 0.8$ \\
Humidity $(\mathrm{RH} \%)$ & $78 \% \pm 12 \%$ & $85 \% \pm 12 \%$ & $73 \% \pm 11 \%$ & $77 \% \pm 11 \%$ & $69 \% \pm 11 \%$ & $68 \% \pm 12 \%$ \\
\hline
\end{tabular}




\subsubsection{The Procedure of Sample Pretreatment}

The instrument parameters of the three-stage cold trap concentrator refer to the USEPA TO-15 method [13]. A certain volume of the gas containing the target compound can be analyzed by the cold trap preconcentration device, and the solvent gas $\left(\mathrm{N}_{2}, \mathrm{O}_{2}, \mathrm{CO}_{2}\right.$, $\mathrm{H}_{2} \mathrm{O}$ ) does not pass through the preconcentration device without entering the chromatographic analysis. Three-stage pre-concentration techniques are commonly used to analyze VOCs in humid air. The first stage of cold trap (glass beads with weak adsorption capacity) is designed to effectively remove water. The cold trap is then heated and the concentrated material is slowly carried with helium or nitrogen into a secondary trap containing Tenax sorbent for efficient removal of $\mathrm{CO}_{2}$. The concentrated gas is heated and backflushed into the tertiary trap. The aim is to further eliminate the interference of water vapor without losing VOCs, and to freeze and concentrate the concentrated gas for rapid injection analysis. In this study, samples were concentrated using Entech Model 7100A VOCs preconcentrator.

\subsubsection{The Analysis Conditions of Chromatography-Mass Spectrometry}

The laboratory analytical instrument is gas chromatography/mass spectrometer (Agilent $7890 / 5975 \mathrm{GC} / \mathrm{MS}$, Agilent, USA), the carrier gas is high purity helium, the purity is $>99.999 \%$, the carrier gas flow is $1.2 \mathrm{~mL} / \mathrm{min}$, and the tail gas is $29 \mathrm{~mL} / \mathrm{Min}$, hydrogen flow rate $30 \mathrm{~mL} / \mathrm{min}$, and air flow rate $300 \mathrm{~mL} / \mathrm{min}$. The column temperature was programmed in two steps, held at $40{ }^{\circ} \mathrm{C}$ and increased to $10{ }^{\circ} \mathrm{C} / \mathrm{min}$ to $140{ }^{\circ} \mathrm{C}$ for 5 minutes, and for 3 minutes at $250{ }^{\circ} \mathrm{C}$ at the rate of $20^{\circ} \mathrm{C} / \mathrm{min}$. The split ratio is $10: 1$, the inlet temperature is $200{ }^{\circ} \mathrm{C}$, the transfer line temperature is $230{ }^{\circ} \mathrm{C}$, the ion source temperature is $130^{\circ} \mathrm{C}$, the quadrupole temperature is $230^{\circ} \mathrm{C}$, and the mass range is 10 $600 \mathrm{am}$. The column was an Agilent DB-5MS, $60 \mathrm{~m} \times 0.32 \mu \mathrm{m} \times 1.0 \mu \mathrm{m}$ (Agilent, USA). Standard gas (1ppm, Linde Spectra Gases Inc, Linde Co., Ltd.) was used to quantify by external standard method. All gas indexes were tested 3 times, the standard deviation analysis accuracy was $\pm 5 \%$, and the standard addition recovery rate was $91 \%-110 \%$.

\subsection{Particle Analysis}

The aerosol mass concentrations of six different compartments were tested in the later period of the voyage. A 24-hour concentration test was performed using a portable aerosol tester (TSI8533, TSI Inc. USA) that monitors Fine Particles $\left(\mathrm{PM}_{2.5}\right)$, Inharable particulates $\left(\mathrm{PM}_{10}\right)$, and total suspended particulate matter (TSP). The sampling flow rate during monitoring was $3.0 \mathrm{~L} / \mathrm{min}$, the detection range was $0.001-150 \mathrm{mg} / \mathrm{m}^{3}$, and the average daily concentration of particulate matter was calculated.

\subsection{Analysis of $\mathrm{CO} / \mathrm{CO}_{2}$}

In this test, $\mathrm{CO}$ and $\mathrm{CO}_{2}$ in the living room were continuously monitored (Konor Model JA903, Konor Electronics, Shenzhen China), the sampling flow rate was $500 \mathrm{~mL} / \mathrm{min}$, the detection range was $0-100 \mathrm{mg} / \mathrm{m}^{3}$, and the $\mathrm{CO}_{2}$ was $0-3 \%$. The monitoring time is not less than 8 hours, and the highest concentration of $\mathrm{CO}_{2}$ was recorded per day. 


\section{Results and Discussion}

\subsection{Analysis of VOC Detection Concentration in Each Compartment}

A total of 34 components were quantitatively detected and divided into five categories, namely aliphatic hydrocarbons, halogenated hydrocarbons, oxygenated compounds, aromatic hydrocarbons and sulfur-containing compounds. As shown in table 2, most of the substances were low in concentration and did not exceed the conventional underwater vehicle military standard of our country (GJB11.3-91) [14] and the American Government Industrial Hygiene Committee (ACGIH) occupational exposure standards [15]. Many pollutants do not have corresponding health standards. ACGIH occupational exposure standard is a time-weighted average of 8 hours working weekday and 40 hours working weekday. While the underwater vehicle's continuous exposure time is significantly longer than 8 hours, the interval period and total exposure time are significantly shorter than the former, so the listed thresholds can only be used as a reference to accurately assess the health hazards of pollutants on boats. As can be seen from the table, the concentrations of oxygen-containing compounds and aromatic hydrocarbon compounds such as aldols are significantly higher than those of sulfides and hydrocarbons. The total amount of pollutants detected in the cabin was $32.7 \mathrm{mg} / \mathrm{m}^{3}$, followed by $21.5 \mathrm{mg} / \mathrm{m}^{3}$ in the machinery compartment, and the least in the energy source section (SS) was $18.4 \mathrm{mg} / \mathrm{m}^{3}$. It can be known that the pollutants produced by human activities and human metabolism account for a large proportion. The main dominant compounds with higher concentration are cyclohexane, dichloromethane, ethanol, acetone, toluene, ethylbenzene and xylene, most of which are in the ppm range, and in which the ethanol in the cabin even reaches $11.3 \mathrm{mg} / \mathrm{m}^{3}$, and the ethanol is too high. The concentration is estimated to be related to the crew drinking. Among these pollutants, there are some low odor thresholds such as dimethyl sulfide and dimethyl disulfide, which are higher in the toilet and other compartments, and the dimethyl disulfide detected in the toilet reaches $0.167 \mathrm{mg} / \mathrm{m}^{3}$, exceeding three times the concentration of the cabin, more than 8,000 times of its odor threshold [16]. These substances in this concentration range will seriously deteriorate the air quality in the cabin and have a strong stimulating effect on the human senses. It is necessary to increase the air quality improvement of these places, such as the installation of purifiers with specific chemical adsorption capacity for these odor substances. From the quantitatively detected substances, such as styrene, toluene, ethylbenzene, xylene and carbon tetrachloride are moderately toxic substances, while benzene, carbon disulfide, chloroform and dimethyl disulfide are highly toxic substances. Though the concentration was from tens to hundreds of ppb, the impact of these components on the cabin environment could not be ignored. Figure 1 shows the concentration accumulation of five types of pollutants. Non-biological sources on the boat such as aliphatic hydrocarbons, aromatic hydrocarbons, halogen and hydrocarbons, mostly are included in themselves, such as the volatilization of the lubricating oil of the ship, the leakage of the refrigerant and the release of the paint, and the natural volatilization due to temperature changes and ventilation, which are influenced greatly by environmental parameters. Bio-sources are closely related to the metabolism and decomposition of organic matter, such as organic acids, sulfides, etc., and their concentrations are significantly correlated with the microbial activity and stability parameters of the source [17]. More toxic compounds such as aromatic hydrocarbons and halogenated hydrocarbons are more important in the power and mechanical cabins. These places 
include diesel engines, coolers, oil pipes, water pipes, filters and auxiliary machines. The bottom compartment of the lower part of the diesel engine is arranged to be slippery. Oil tanks, slop tanks, and diesel engine cooling fresh water tanks, these two types of nonbiological compounds are more abundant. The noise and the ambient temperature in the cabin is high which is the cabin with the worst environmental conditions on the underwater vehicle, in places where activities such as cabins and command rooms are densely populated, and a large number of oxygenated substances such as aldols are detected, which is closely related to personnel activities and diet.

Table 2. The identified pollutants of six sampling location in this campaign.

\begin{tabular}{|c|c|c|c|c|}
\hline \multirow{2}{*}{$\begin{array}{l}\text { Pollutant } \\
\text { Group }\end{array}$} & \multirow[b]{2}{*}{ Name } & \multirow{2}{*}{$\begin{array}{l}\text { Permissible } \\
\text { Concentration } \\
{[14]}\end{array}$} & \multirow{2}{*}{ TLV-TWA [15] } & Concentrations $\left(\mathbf{m g} / \mathbf{m}^{3}\right)$ \\
\hline & & & & 1-AS 2-T 3-CR4-G 5-SS 6-MR \\
\hline \multirow[t]{3}{*}{ Aliphatic } & n-Hexane & -- & 1920 & 0.5650 .4520 .5070 .5530 .4580 .518 \\
\hline & Cyclohexane & -- & 375 & $\begin{array}{llllll}2.21 & 1.99 & 1.86 & 1.33 & 2.00 & 1.92\end{array}$ \\
\hline & n-Heptane & 75 & 1786 & $\begin{array}{lll}0.6670 .3290 .7651 .03 & 0.7040 .573\end{array}$ \\
\hline \multirow[t]{10}{*}{ Halogenated } & I Chloromethane & -- & -- & 0.1890 .1520 .1500 .0580 .1400 .144 \\
\hline & Chloroethane & -- & -- & 0.0190 .0190 .0170 .0100 .0170 .015 \\
\hline & Chloroethylene & -- & -- & 0.0070 .0080 .0070 .0070 .0070 .007 \\
\hline & Dichloromethane & 87.5 & 167 & $\begin{array}{lllll}1.17 & 1.06 & 1.00 & 0.6270 .990 & 1.03\end{array}$ \\
\hline & 1,1-Dichloroethane & -- & 400 & 0.0280 .0190 .0180 .0110 .0140 .019 \\
\hline & Trichloromethane & -- & 50 & 0.1260 .0980 .0930 .0630 .0800 .100 \\
\hline & 1,2-Dichloroethane & 87.5 & 400 & 0.2270 .1490 .1630 .1290 .1820 .154 \\
\hline & Tetrachloromethane & -- & 30 & 0.3670 .3290 .3040 .2560 .3370 .322 \\
\hline & Trichloroethylene & -- & 292 & 0.0190 .0150 .0150 .0150 .0150 .016 \\
\hline & 1,2-Dichloropropane & -- & 5 & 0.0360 .0340 .0420 .0340 .0400 .040 \\
\hline \multirow[t]{6}{*}{ Oxygenated } & Ethanol & 300 & 2054 & $\begin{array}{llllll}11.3 & 2.04 & 3.15 & 2.42 & 2.47 & 1.01\end{array}$ \\
\hline & Acetone & -- & 1295 & $\begin{array}{llllll}3.36 & 2.70 & 2.54 & 1.07 & 1.82 & 2.69\end{array}$ \\
\hline & Methyl tert butyl ether & -- & 643 & 0.0640 .0800 .0580 .0270 .0370 .078 \\
\hline & 2-Butanone & -- & & 0.4250 .4990 .3360 .3490 .2900 .38 \\
\hline & Ethyl acetate & -- & 1571 & $\begin{array}{llll}1.24 & 2.45 & 0.6341 .19 & 0.9102 .39\end{array}$ \\
\hline & Methyl methacrylate & -- & 223 & $\begin{array}{lll}0.5890 .2590 .4800 .6341 .06 & 0.527\end{array}$ \\
\hline \multirow[t]{12}{*}{ Aromatic } & Benzene & 6.0 & 1.5 & 0.3190 .1670 .3180 .2130 .3070 .282 \\
\hline & Toluene & 40 & 13.5 & $\begin{array}{llllll}3.88 & 2.69 & 2.55 & 2.07 & 1.92 & 3.91\end{array}$ \\
\hline & Ethyl benzene & 30 & 435 & $\begin{array}{llllll}2.19 & 1.18 & 1.72 & 2.52 & 1.57 & 1.97\end{array}$ \\
\hline & p-Xylene & -- & 435 & $\begin{array}{llll}1.00 & 0.7340 .6851 .46 & 0.6820 .792\end{array}$ \\
\hline & m-Xylene & -- & 435 & $\begin{array}{lll}0.6880 .4340 .6171 .12 & 0.7010 .778\end{array}$ \\
\hline & o-Xylene & -- & 435 & 0.8370 .4080 .5830 .9870 .6320 .682 \\
\hline & Styrene & --- & 80 & 0.1240 .0570 .0870 .1200 .0910 .097 \\
\hline & 4-Ethyl toluene & -- & -- & 0.0790 .0420 .0650 .1370 .0870 .050 \\
\hline & 1,3,5-Trimethyl benzene & -- & -- & 0.0920 .0430 .0680 .1100 .0800 .042 \\
\hline & 1,2,4-Trimethyl benzene & -- & -- & 0.3140 .1540 .2320 .5230 .3220 .153 \\
\hline & Chlorobenzene & -- & 55 & 0.1000 .0720 .0460 .0200 .0230 .128 \\
\hline & 1,4-Dichlorobenzene & -- & 142 & 0.2110 .2200 .2890 .1530 .1330 .334 \\
\hline \multirow[t]{3}{*}{ Sulfur } & Dimethylsulfide & -- & -- & 0.0250 .0760 .0750 .0680 .0560 .066 \\
\hline & Dimethyldisulfide & -- & 25.4 & 0.0520 .1670 .0850 .0820 .0460 .109 \\
\hline & Carbon disulfide & -- & 3.11 & 0.2230 .1880 .1930 .2130 .1940 .186 \\
\hline
\end{tabular}

TLV-TWA (Threshold Limit Values-Time Weighted Average), the data come from "American Conference of Governmental Industrial Hygienists (ACGIH)"; --, no reported. 


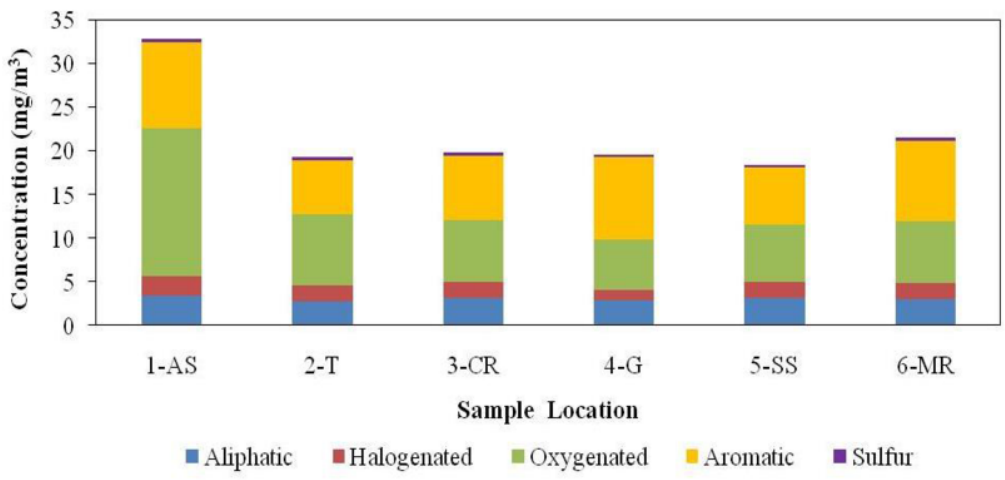

Figure 1. Concentrations of five pollutant families in the six cabins.

\subsection{Analysis of the Concentration of Particle}

According to the size of the particle size, the particles can be divided into three types: particles with a particle size of less than $2.5 \mu \mathrm{m}$ are called Fine Particles $\left(\mathrm{PM}_{2.5}\right)$; particles with a particle size of less than $10 \mu \mathrm{m}$ are called Inhalable particulates $\left(\mathrm{PM}_{10}\right)$; All suspended particulates with a particle size of less than $100 \mu \mathrm{m}$ are referred to as Total Suspended Particulates (TSP) [18]. $\mathrm{PM}_{10}$ can stay in the atmosphere for a long time and is one of the main pollutants in the daily atmosphere [19]. $\mathrm{PM}_{2.5}$ is the most part of the $\mathrm{PM}_{10}$, it has a small particle size and can absorb a large amount of toxic and harmful substances such as heavy metals and pathogenic bacteria, and it has a long residence time in the atmosphere and a long transport distance, which has an effect on visibility, air quality. and human health has a greater impact [20].

The monitoring was carried out from the 13th to the 18th day of navigation. The average concentration of $\mathrm{PM}_{2.5}$ and $\mathrm{PM}_{10}$ in each compartment was higher than the concentration level at the time of mooring, indicating that certain aerosol pollution occurred in the cabin, as shown in figure 2. China's military standards do not have the limit of particulate matter. The national standard "Indoor Air Quality Standards" (GB/T18883-2002) stipulates that the daily average concentration of $\mathrm{PM}_{10}$ concentration limit is $0.15 \mathrm{mg} / \mathrm{m}^{3}$, and $\mathrm{PM}_{2.5}$ has no standard [21]. The cabins with daily average concentration of $\mathrm{PM}_{10}$ exceeding the national standard $\mathrm{GB} / \mathrm{T} 18883-2002$ have accommodation AS $\left(0.346 \mathrm{mg} / \mathrm{m}^{3}\right)$, command room CR $\left(0.503 \mathrm{mg} / \mathrm{m}^{3}\right)$, kitchen $\mathrm{G}(0.482$ $\left.\mathrm{mg} / \mathrm{m}^{3}\right)$ and mechanical cabin MR $\left(0.469 \mathrm{mg} / \mathrm{m}^{3}\right)$. According to the above analysis, the cabin aerosol in the submerged state of the boat belongs to fine particulate matter pollution. In the indoor environment, $\mathrm{PM}_{2.5}$ mainly has two forms of primary particles directly discharged in a solid form and secondary particles generated by a chemical reaction [22]. The primary particles are derived from the combustion of fuel, the emission of decorative materials and furniture surfaces, the use of equipment, the secondary suspension of fine particles, the condensation of particles less than $2.5 \mu \mathrm{m}$, the air conditioning system and the activities of indoor personnel such as smoking, breathing, coughing, walking, and cleaning. The secondary particles are mainly secondary fine particles of nitrate and sulfate formed by multiphase chemical reaction. We speculate that the main sources of fine particles in the underwater vehicle cabin environment are human body emissions, material surface grinding and shedding, mechanical equipment operation and personnel operations. 
Figure 3 shows the change of aerosol mass concentration with time passing after the $\mathrm{LiOH}$ absorption device outside the cabin is opened (14:39). It can be found that at the instant of opening of the $\mathrm{LiOH}$ absorption device, the aerosol concentration of the three particle sizes in the cabin rapidly increases, and then the concentration gradually decreases, thereby it can be known that the opening of the $\mathrm{LiOH}$ absorption device has a large influence on the aerosol concentration of the cabin.

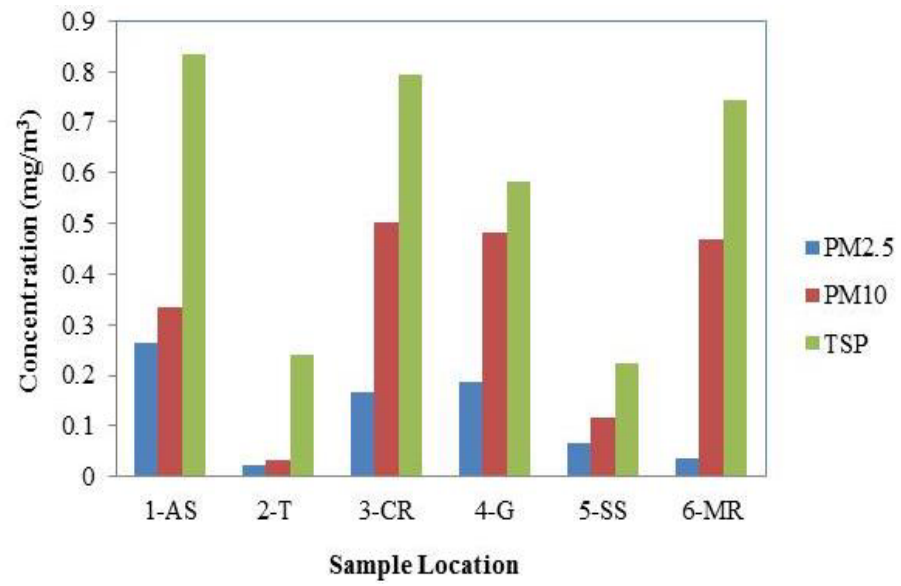

Figure 2. Particle mass concentration of three size in the six cabins.

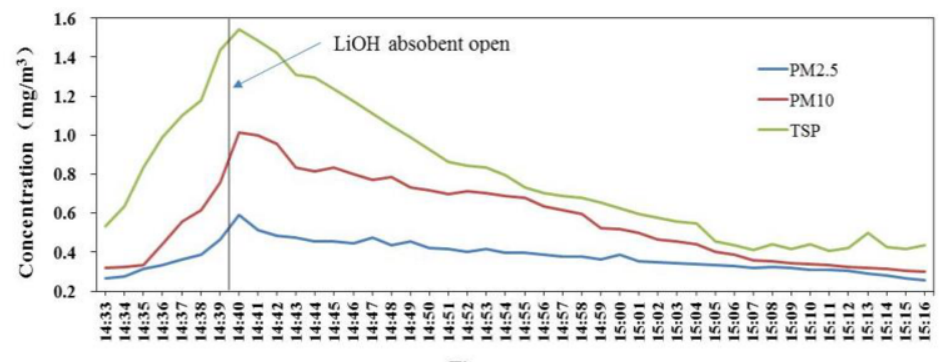

Time

Figure 3. Fluctuation of particle mass concentration during an operation of $\mathrm{LiOH}$ exchange in accommodation space.

\subsection{Analysis of $\mathrm{CO} / \mathrm{CO}_{2}$ Detection Concentration}

The highest concentration distribution of $\mathrm{CO}$ and $\mathrm{CO}_{2}$ in the underwater vehicle cabin was shown in figure 4. CO condenses will be up to hemoglobin by breathing and forms carboxyhemoglobin after passing through the bubble membrane. The ratio of the hemoglobin affinity between to $\mathrm{CO}$ and to the oxygen is about $235: 1$. The main mechanism of toxic effects of $\mathrm{CO}$ on mammals is to reduce the oxygen delivery capacity of blood. Long-term CO poisoning may cause myocarditis and even myocardial infarction, and its severity increases with the increase of $\mathrm{CO}$ concentration in blood. China military standard (GJB11.3-91) [14] has a CO concentration limit of $23 \mathrm{mg} / \mathrm{m}^{3}$. During the voyage, $\mathrm{CO}$ is at this standard limit, and the underwater navigation concentration is higher than that of water navigation. $\mathrm{CO}_{2}$ is one of the main components of air pollutants in underwater vehicle cabins, and high concentrations can cause 
asphyxiation. The underwater vehicle crew is the main source of $\mathrm{CO}_{2}$ in the cabin [23]. Long-term exposure to high $\mathrm{CO}_{2}$ concentrations can cause people to feel chest tightness, dizziness, and decreased response capacity. At the same time, the concentration of $\mathrm{CO}_{2}$ is often used to characterize the degree of indoor air circulation and reflect the level of other harmful pollutants in the air. If the crew are exposed to the $\mathrm{CO}_{2}$ environment whose condense is $3 \%$ for dozens of hours, the working ability and intellectual activity of all people are significantly reduced. If the condense is more than $5 \%$, the environment can seriously impair vision and hearing. After exposure to $1.5 \% \mathrm{CO}_{2}$ gas for several ten days, the $\mathrm{pH}$ of the chronic respiratory acid and the electrolyte balance showed obvious adaptive changes. It will not fully recover even after leaving this environment for several days, which indicates that long-term exposure to this concentration may lead to change of pathology and physiological. Data collected from nine nuclear-powered ballistic missile underwater vehicle $\mathrm{s}$ showed that the average concentration of $\mathrm{CO}_{2}$ was $0.35 \%$ and the concentration ranged from 0 to $1.1 \%$. The data collected from ten nuclearpowered attack underwater vehicles showed that the average concentration of $\mathrm{CO}_{2}$ was $0.41 \%$ and the concentration ranged from $0.03 \%$ to $1.13 \%$ [24]. The concentration of $\mathrm{CO}_{2}$ in China's conventional underwater vehicle military standard (GJB11.3-91) is 1\%, and the highest concentration of $\mathrm{CO}_{2}$ on the $18^{\text {th }}$ and $35^{\text {th }}$ days of navigation exceeds the standard limit, which is $1.12 \%$ and $1.21 \%$, respectively.

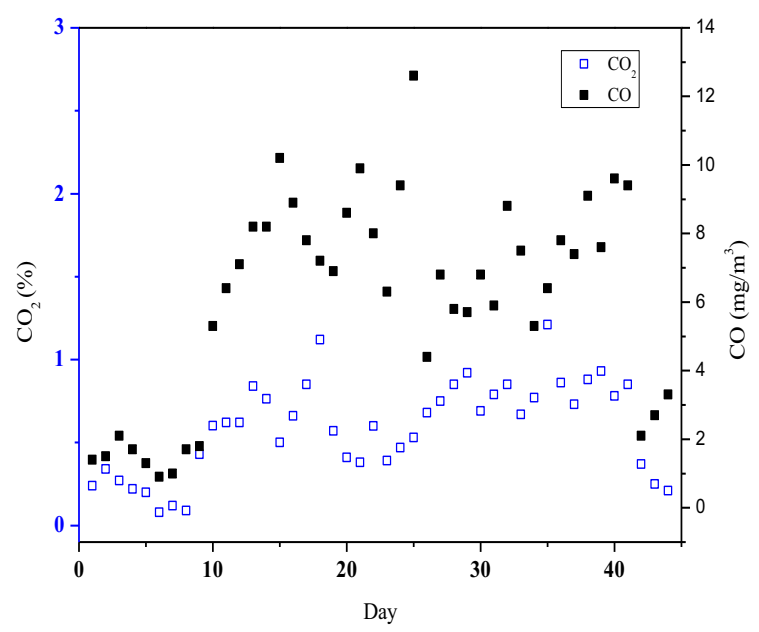

Figure 4. Distribution of maximum concentrations of carbon monoxide and carbon dioxide in accommodation space.

\section{Conclusion}

We recommend the revision and improvement of the allowable concentration of air components in the underwater vehicle compartment, adding some standards for low odor thresholds and highly toxic components. The standards of underwater vehicle air quality should be carried out as soon as possible. Control low odor threshold gas components can improve the quality of the ambient air of the ship cabin, and further the screening of non-metallic materials used on the ship should be made. For toilets, kitchens, washrooms and other areas with strong source strength, we should strengthen hygiene and operation 
management and establish some special purification facilities to further improve the air quality inside the boat.

\section{Acknowledgements}

This work was financially supported by the Navy Foundation of China, National Natural Science Foundation of China (NO. 21507161).

\section{References}

[1] Liu H and Zhu D 2011 Development of AIP technology and its effect for submarine operation Journal of Sichuan Ordnance 32 (9) 28-29.

[2] Hu J, Sun J, Zhou Z and Hao H 2018 Development status and trend analysis of foreign AIP technology Ship Electronic Engineering 285 (3) 9-11.

[3] Peng G 2006 A Study on the cabin atmosphere control system of AIP submarines Chinese Journal of Ship Research 1 (2) 62-65.

[4] Zhang H 2006 Submarine atmosphere pollution and detection technology Ship Science and Technology 28 (2) 6-8.

[5] Rönkkö T J, Jalava P I, Happo M S, et al. 2018 Emissions and atmospheric processes influence the chemical composition and toxicological properties of urban air particulate matter in Nanjing, China Science of the Total Environment 639 (15) 1290-1310.

[6] Wang S and Zhou S 2001 The status of submarine atmospheric component analysis Ship Science and Technology 23 (3) 22-25.

[7] Yuan X and Zhang H 2002 Review of submarine atmospheric component analysis technology Enclosed Environment Analysis and Control Academic Seminar.

[8] Zhou S, Ma J and Wang S 1992 Qualitative analysis of volatile organic compounds in submarine atmosphere by gas chromatography/mass spectrometry Ship Science and Technology 2 26-32.

[9] Xiao C, Wang T, Liu H and Chen Q 2003 Study on air composition of submarine chambers Journal of Prevention Medicine of Chinese People's Liberation Army 21 (2) 16-18.

[10] Ola P, Christina S and Joakim P 2006 Air contaminants in a submarine equipped with air independent propulsion Journal of Environmental Monitoring (8) 1111-1121.

[11] Gan T H, Hanhela P, Mazurek W and Gillett R 2010 Show more characteristics of submarine engine diesel particulates in the maritime environment Journal of Aerosol Science (41) 23-35.

[12] Claeys M, Wang W, Vermeylen R, Kourtchev I, Chi X, Farhat Y, Surratt J D, Gómez-González Y, Sciare J and Maenhaut W 2010 Chemical characterisation of marine aerosol at Amsterdam Island during the austral summer of 2006-2007 Journal of Aerosol Science 41 (1) 13-22.

[13] US-EPA 1999 Compendium Method TO-15, Determination of Volatile Organic Compounds (VOCs) in Air Collected in Specially-Prepared Canisters and Analyzed by Gas Chromatography/Mass Spectrometry (GC/MS) (Cincinnati, USA).

[14] 1991 Permissible Concentration of Atmosphere Composition Aboard Diesel Submarine Compartments (Beijing : National Defense Science and Technology Industry Committee) GJB 11.3-91.

[15] 2013 ACGIH, TLV and BELs Threshold Limit Values for Chemical Substances and Physical Agents \& Biological Exposure Indices with 7th Edition Documentation.

[16] Fang J, Yang N, Cen D, Shao L and He P 2012 Dour compounds from different sources of landfill: Characterization and source identification Waste Management 32 (7) 1401-1410.

[17] Fang J, Liu H, Chen S, Xun L, Xu X and Xiao C 2014 Odor pollutants in ship cabin and priority control The Administration and Technique of Environmental Monitoring 3 11-15.

[18] Hou B, Zhuang G S and Zhang R 2011 The implication of carbonaceous aerosol to the formation of haze: Revealed from the characteristics and sources of OC/EC over Amega-city in China Journal of Hazardous Materials 190 (1) 529-536.

[19] Tiwari S, Bisht D S and Srivastava A K 2014 Variability in atmospheric particulates and meteorological effects on their mass concentrations over Delhi India Atmospheric Research 145/146 45-56.

[20] PoPe C A, Bumett R T, Thun M J, et al. 2002 Lung cancer, cardiopulmonary mortality, and long term exposure to fine particulate air pollution American Medicine Association 287 (9) 1132-1141.

[21] 2012 Indoor Air Quality Standards (Beijing: Ministry of Environmental Protection of China) GB/T18883-2002. 
[22] Zhu M and Wen Y 2014 The discussion on indoor PM 2.5 concentration standard Refrigeration and Air Conditioning 28 (6) 726-730.

[23] Crawl J R 2003 Review/updating of limits for submarine air contaminants First Meeting on Emergency and Continuous Exposure Guidance Levels for Selected Submarine Contaminants (Washington, DC).

[24] Hagar R 2003 Submarine atmosphere control and monitoring brief for the COT committee First Meeting on Emergency and Continuous Exposure Guidance Levels for Selected Submarine Contaminants (Washington, DC). 